\title{
A relação entre a memória social e sociocognição: busca do contexto social na Organização do Conhecimento
}

\author{
Juliana Rabelo do Carmo \\ Mestra; Universidade Federal de Santa Catarina, Florianópolis, SC, Brasil; \\ juliana.rabello@yahoo.com.br \\ Cezar Karpinski \\ Doutor; Universidade Federal de Santa Catarina, Florianópolis, SC, Brasil; \\ cezar.karpinski@gmail.com \\ Marisa Bräscher \\ Doutora; Universidade Federal de Santa Catarina, Florianópolis, SC, Brasil; \\ marisa.brascher@gmail.com
}

\begin{abstract}
Resumo: Este artigo tem como objetivo evidenciar a relação entre memória social e cognição social e as perspectivas de compreensão do contexto para organização do conhecimento. A pesquisa é exploratória e adota como procedimento metodológico a pesquisa bibliográfica. $\mathrm{O}$ estudo compreende a memória social como fonte de conhecimento que pressupõe a experiência coletiva de um grupo. Caracteriza a sociocognição, os estudos sobre a linguagem e as discussões que este campo contempla sob a perspectiva do paradigma da cognição social. Aponta a interseção entre a memória social e a sociocognição, no ponto em que, para a interpretação da memória é necessário a compreensão do seu contexto, que possui características sociocognitivas de seus interlocutores, ou seja, a visão de mundo de quem o interpreta. O campo da memória discursiva sociocognitiva é interpretado como o âmbito onde se constituem as práticas sociocomunicativas de representação e memória. A pesquisa mostra que as questões sobre o discurso, os contextos de uso, as intenções comunicativas e sociais efetivadas pelos falantes são elementos de estudo no campo da memória discursiva sociocognitiva. Constata que a base indicada pela sociocognição para os estudos da memória social, fornece subsídios para a organização do conhecimento no que diz respeito às formas como as comunidades discursivas produzem e organizam seus conhecimentos socialmente construídos.
\end{abstract}

Palavras-chave: Memória social. Sociocognição. Memória discursiva sociocognitiva. Organização do conhecimento. 


\section{Introdução}

A proposta deste artigo é discutir como se dá a interconexão entre os conceitos de memória social, de Fentress e Wickham (1992), e sociocognição, de Ingedore Koch e Cunha-Lima (2011). O principal objetivo é demonstrar que a relação entre memória social e sociocognição abre novas perspectivas de estudos sobre o contexto na Organização do Conhecimento. Neste recorte da Ciência da Informação (CI), destaca-se a possibilidade da análise de domínios em comunidades discursivas, que, segundo Amorim (2015), são os grupos que não apenas enunciam discursos por meio de documentos, mas que também tratam, disponibilizam, buscam e recuperam a informação e o conhecimento.

O estudo caracteriza-se como pesquisa exploratória ao reunir dados, informações, ideias ou hipóteses sobre um problema de pesquisa com a visão de indicar pesquisas futuras (COLLIS; HUSSEY, 2005), e utiliza a pesquisa bibliográfica para nortear o levantamento de estudos sobre as temáticas.

Embora a conceituação de memória na CI tenha seu significado implícito aos contextos onde ocorrem os fluxos de informação, Jardim elenca que "[...] diversos termos tendem a ser associados à memória, tais como: resgate, preservação, conservação, registro, seleção; sendo a categoria preservação a mais utilizada." (JARDIM, 1995, p. 1). Além desse ponto, entende-se que a temática da memória na CI pode ser analisada por outras óticas, conforme apresentam Oliveira e Rodrigues (2008) ao citar Capurro (2003 ${ }^{1}$ ), no que diz respeito aos novos modelos físicos, sociais e cognitivos.

Em linhas gerais, os estudos que definem o conceito de memória são uma rubrica geral de investigação com intuito de analisar as distintas maneiras pelas quais o indivíduo se molda ou é moldado por aquilo que entende como passado. De acordo com Olick e Robins (1998), o modo como a memória constitui o indivíduo pode ser individual ou coletiva, material ou comunicativa e de modo consensual ou conflituoso.

De forma semelhante ao que acontece com o indivíduo, cuja memória toma forma a partir de influências distintas, os estudos sobre a memória também são moldados no decorrer de um processo histórico. Neste caso, a influência 
vem dos complexos sistemas que estruturam a sociedade, cujas principais vertentes advém dos conflitos ou relações entre a ciência, política, cultura, religião, entre outras.

Tendo isto em mente, escolheu-se a categoria "memória social" de Fentress e Wickham (1992) por ser a que ultrapassa a discussão fenomenológica da memória individual ou coletiva. Ao discorrer sobre o papel da memória no campo epistemológico, os autores possibilitam o diálogo com várias áreas do conhecimento, entendendo o conceito de memória como interdisciplinar.

Basicamente, Fentress e Wickham (1992) defendem uma perspectiva teórica voltada para o tratamento da memória como fonte de conhecimento, pois, nesta perspectiva, a memória leva em consideração fatores socioculturais de um contexto onde o conhecimento é produzido, organizado e comunicado. Isto corrobora com as discussões feitas em torno da cognição social e seus principais pressupostos, em especial, suas contribuições para a sociocognição e as questões da linguagem em suas vertentes de estudos. Vale ressaltar que na sociocognição o enfoque da linguagem se distancia das questões estruturalistas como a gramática, por exemplo - e estabelece uma proximidade com os estudos sobre a semântica nos textos, o que se reflete na grande produção científica deste campo voltada para questões como as práticas, uso e análise do discurso, ou seja, discussões que estão relacionadas à Linguística Textual, abordagem essa que nos parece ir ao encontro das necessidades da Organização do Conhecimento, no tocante ao tratamento temático da informação, processo que também se volta aos aspectos semânticos dos textos para a extração de seus conteúdos.

No entanto, como destaca Hjorland (2002), os produtos intelectuais sofrem influência dos sujeitos que compõem o grupo que os criou e validou, e, sendo assim, a organização do conhecimento não deve desconsiderar os aspectos sociais implicados nas representações geradas. Nessa direção, os estudos da sociocognição podem contribuir para a compreensão dos contextos em que ocorrem os processos informacionais e, assim, para o aprimoramento das representações do conhecimento. 
A sociocognição é compreendida como uma abordagem que considera o meio social como elemento que influencia no que se aprende e onde se realiza o aprendizado (HIGGINS, 2000). Em outras palavras, o contexto é determinante para a apreensão do conhecimento e para as formas de representação por meio da linguagem.

Feitas estas considerações, esta pesquisa parte da indagação sobre as potenciais contribuições que os estudos sobre a memória e a sociocognição podem trazer para a Organização do Conhecimento. Para isso, neste trabalho apresenta-se o conceito de memória social e caracteriza-se a sociocognição. Os pontos de encontro entre estas duas áreas também são discutidos no campo da memória discursiva sociocognitiva - onde se identificam indicativos da memória nos atos discursivos dos grupos. Ressalta-se aqui, o entrelaçamento com as bases em que se apoia a abordagem pragmática da Organização do Conhecimento, em especial, os estudos das comunidades discursivas.

\section{Memória social como fonte de conhecimento: contribuições da abordagem de Fentress e Wickham}

Os estudos sobre memória refletem os contextos econômicos, políticos e culturais da sociedade em que os estudiosos da área se situam. Tendo em vista este pressuposto, convém lembrar, em síntese, algumas das principais teorias que antecederam a perspectiva de Fentress e Wickham (1992) para compreensão sobre a evolução dos conceitos de memória e o "desajuste" de abordagens anteriores na constituição deste campo de pesquisa atualmente.

A evolução do conceito de memória e as discussões que englobam esse tema se desdobraram em três prismas principais: a perspectiva de memória individual apontada por Henri Bergson no final do Século XIX, a teoria da memória coletiva publicada em 1950 por Maurice Halbwachs, e o enfoque sobre a memória subterrânea de Michel Pollak já na década de 1980.

Henri Bergson é um dos primeiros filósofos a definir, em 1896, a memória enquanto mecanismo epistemológico. De acordo com Montysuma e Karpinski (2010), Bergson (1999²) defende que o conhecimento advém de um processo onde as lembranças são elos ou pontos de interseção entre matéria e 
espírito ou, se preferirmos, entre o sujeito e o objeto. O objeto passa a ser apenas uma imagem que, no momento da percepção humana, se integra a um conjunto de lembranças. Neste sentido, o passado se torna apenas uma ideia e o presente o "ídeo-motor", defendendo, assim, a inexistência de "percepção pura do presente", pois percepções humanas estão sempre "misturadas" às lembranças.

A memória, praticamente inseparável da percepção, intercala o passado no presente, condensa também, numa intuição única, momentos múltiplos da duração, e assim, por sua dupla operação, faz com que, de fato, percebamos a matéria em nós, enquanto de direito a percebemos nela. (BERGSON, 2010, p.77).

Dessa forma, Bergson (2010) inaugura a concepção de que a memória é um fenômeno que acontece sempre no presente, no atual momento em que as imagens tocam o corpo e os mecanismos das lembranças vêm ao consciente transformando o que se vê em objetos conhecidos ou não.

Ainda de acordo com Montysuma e Karpinski (2010), o caráter subjetivo das lembranças torna a memória um fenômeno individual, pois só dependerá do indivíduo a sobrevivência das imagens do passado. "Cada indivíduo conserva suas lembranças na medida em que elas lhes são úteis para as experiências ou desafios do presente, ocorrendo sempre uma subsunção entre as lembranças atuais e as adquiridas pelo tempo.” (MONTYSUMA; KARPINSKI, 2010, p. $30)$.

O principal crítico da teoria bergsoniana de memória foi um dos seus próprios alunos, Maurice Halbwachs, cuja publicação póstuma La Mémoire Collective, de 1950, visa mostrar como Bergson estava equivocado no seu conceito individual de memória. Halbwachs foi um dos seguidores da sociologia de Durkheim que, segundo Guimarães e Gomide (2011), é considerado um teórico funcionalista cujo princípio é a concepção de que as consciências individuais são determinadas pela sociedade. Fortemente influenciado por esta linha de raciocínio, Halbwachs (2004) elaborou o conceito de memória coletiva. Em linhas gerais, o pensamento do autor se refere a uma identidade coletiva que se constrói no interior de um grupo, em contraposição a uma perspectiva individual, bem como separa a memória da história estabelecendo que só pode haver história quando não houver resquício na memória coletiva. 
Para Montysuma e Karpinski, o conceito de memória coletiva de Halbwachs (2004) é uma forma crítica de mostrar que o indivíduo e tudo o que ele produz, pensa ou conhece, é determinado pelo meio em que está inserido. Dessa forma, a memória “[...] não emerge do interior do indivíduo, mas é alavancada por fatores coletivos, sempre intencionais e com objetivos suscitados pelo presente, externos ao sujeito, na interface sujeito-espaço coletivo." (MONTYSUMA; KARPINSKI, 2010, p. 31). Contudo, da mesma forma que Bergson (2010), Halbwachs (2004) constrói uma teoria fundamentalista, tirando do sujeito toda e qualquer margem de liberdade tanto no processo de cognição quanto de preservação de suas lembranças, o que, de acordo com alguns críticos, não serve para explicar o fenômeno da memória.

Um dos principais críticos de Halbwachs (2004) é Michel Pollak, sociólogo e historiador austríaco que pesquisou o Holocausto a partir das memórias de sobreviventes. Para este autor, a memória coletiva de Halbwachs (2004) pode ser confundida com a memória de "um" coletivo, no sentido de um grupo ou classe social. Dessa forma, a memória coletiva passa a ser aquilo que alguém definiu como coletiva. No caso da Europa Ocidental, quem teve a primazia desta definição foram os Estados Nacionais que, a partir de mecanismos de defesa de algumas memórias - arquivos, museus, monumentos, patrimônios - construíram "memórias oficiais" que definiram, posteriormente, as histórias nacionais.

Pollak (1989) afirma que a memória coletiva apontada por Halbwachs (2004) não se aplicaria como fundamento teórico da história, uma vez que a memória é um elemento constituinte do sentimento de identidade, e por este motivo, é fruto de disputas de memórias marginalizadas e silenciadas, pertencentes a uma minoria.

A concepção de memória para Pollak (1989) se aproxima de Halbwachs (2004) no que diz respeito ao seu fenômeno coletivo, porém, o ponto principal de divergência entre estas duas visões se encontra na percepção de Pollak (1989) de que independente do contexto social em que o indivíduo se encontra inserido, a ele é permitido o acesso às suas memórias individuais, fato que permite as suas próprias lembranças ou esquecimentos. 
As fragilidades destas teorias incidem em dois pontos: no afastamento da questão da memória enquanto elemento da história e, principalmente, à aceitação do indivíduo ao determinismo coletivo, deixando de lado questões relativas ao tratamento da memória como fonte de conhecimento.

Nessa perspectiva, Fentress e Wickham (1992) se posicionam trazendo importantes considerações sobre o lado público e social da memória, ao abordar a ação de falar ou escrever sobre memórias para reencenar o passado por meio do uso da palavra. Segundo os autores, a memória transpassa por todos os aspectos da vida mental, desde as abstratas, cognitivas até as mais físicas e inconscientes, ressaltando, assim, que a memória está sempre em ação em nossas mentes, integrando subjetivamente informações e sentimentos como partes integrais dos indivíduos.

A questão da distinção entre o fato objetivo e a interpretação subjetiva é situada na estrutura da memória. Fentress e Wickham (1992) explicam que este fato descortina o modelo textual como uma concepção de memória, a exemplo das histórias orais, que uma vez materializadas nos documentos, agregam informações sobre o passado que revelam possibilidades a serem exploradas. Por este motivo a nova perspectiva do passado para os autores consiste na formação dos "documentos orais" e pelas informações que carregam como uma abordagem para a memória social.

Vale ressaltar que na visão dos autores o modelo textual é considerado uma analogia, tendo em vista que, na mente, a memória é entendida apenas como pensamento, e textos são objetos físicos. Em contraposição, elucida-se que se o indivíduo não tiver a possibilidade de separar um texto de outro, dificilmente pode analisá-los criticamente, mas esta separação ou seleção é mentalmente viável quando se trata de memória (FENTRESS; WICKHAM, 1992).

Em suma, o que torna a memória utilizável como fonte e reforça seu aspecto social, consiste no fato de que podemos articulá-la e comunicá-la primeiro em palavras com mais facilidade do que com memória da experiência pessoal associada a um contexto histórico amplo. 
Nesse sentido, convém ressaltar um ponto, a correlação entre a Psicologia cognitiva - que possui como sub-área a cognição social -, e a memória. Esta questão é abordada por Fentress e Wickham (1992) a partir da necessidade de psicólogos cognitivos e filósofos empiristas de tentar entender as problemáticas que envolvem a concepção textual da memória.

Este pressuposto baseia-se no pensamento de Endel Tulving, considerado um dos principais estudiosos de memória, que apregoa que nossas memórias estão divididas em pelo menos dois "sistemas" - um "sistema de memória semântica" e um "sistema de memória episódica", sendo que estes sistemas estão implícitos a duas formas diferentes de consciência (TULVING, 1983).

Tulving (1983) explica ainda que a memória semântica - que viabiliza a lembrança por meio dos signos -, governa nosso conhecimento de eventos independentemente de nossa própria experiência pessoal, enquanto a memória episódica se encontra subjacente ao nosso senso subjetivo de identidade.

Essa diferenciação é considerada de natureza epistemológica, uma vez que, a memória racionalmente organizada, ou seja, ordenada como uma rede de conceitos se difere da experiência não racionalmente organizada, sequenciada temporalmente e definida como "episódica” (FENTRESS; WICKHAM, 1992).

Em contrapartida, essa abordagem é considerada vulnerável por Fentress e Wickham (1992), uma vez que dependendo do contexto, no caso de uma cultura não alfabetizada, por exemplo, seria inaplicável essa distinção, pela inexistência de um referencial simbólico (palavras/conceitos) visualmente orientado, no que diz respeito à correspondência com as imagens representativas das memórias.

Se por um lado, Fentress e Wickham (1992) entendem que a distinção entre o semântico e o episódico não é manifesto em todas as culturas, devido a condicional existência de um entendimento de conhecimento semanticamente estruturado como o nosso, por outro eles indicam caminhos possíveis.

O próprio conceito de memória social definido por Fentress e Wickham (1992) compreende uma expressão de experiência coletiva onde a memória social identifica um grupo, dando-lhe um sentido do seu passado e definindo 
seus anseios para o passado. Em suma, "memória social" significa uma fonte de conhecimento ao propiciar elementos para uma reflexão consciente do passado, possibilitando interpretações de categorias pelas quais um grupo (re) conhece o ambiente sociocultural em que estão inseridos.

Porém, a conclusão de que Fentress e Wickham (1992) é de que existem dois caminhos possíveis para sua teoria: primeiro, a atribuição da razão aos historiadores ao considerar que a memória é vital somente quando possui um contexto que indica o seu início histórico. Segundo que, apesar disto, não devemos aceitar a memória social de forma passiva e acrítica, mas o que se propõe é estabelecer um diálogo com a história - uma vez que memória social é a história de sua transmissão.

A partir dessas considerações, estruturamos uma síntese sobre os conceitos de memória que embasam a discussão deste estudo a partir do entendimento e abordagens sobre memória dos autores utilizados como referencial teórico, conforme mostra o Quadro 1, de forma a estabelecer uma diferença clara entre os pontos de vista.

Quadro 1 - Síntese do conceito de memória para Pollak, Fentress e Wickham, Bergson e Halbwachs

\begin{tabular}{|c|c|c|}
\hline Autor & Abordagem & Conceito de memória \\
\hline Bergson (2010) & $\begin{array}{c}\text { Epistemológico e } \\
\text { individual }\end{array}$ & $\begin{array}{c}\text { Fenômeno que acontece no presente por meio de associação } \\
\text { de um conjunto de lembranças; percepção humana somada às } \\
\text { lembranças. }\end{array}$ \\
\hline Halbwachs (2004) & $\begin{array}{c}\text { Coletivo e } \\
\text { individual }\end{array}$ & Memórias são determinadas pelo meio em que o indivíduo \\
está inserido, ou seja, são construídas no grupo.
\end{tabular}

Fonte: Elaborado pelos autores. 
Para alcance da finalidade de discutir as interseções entre a memória e sociocognição, e ainda, as contribuições dessa relação para a perspectiva pragmática na Organização do Conhecimento, entendemos que o ponto de vista mais adequado para essa análise é a abordagem social de Fentress e Wickham (1992) que indicam o conceito de memória como fonte de conhecimento, ao considerar a noção contextual como fundamental para compreensão da produção, organização e comunicação do conhecimento.

\section{Sociocognição: a linguagem sob a perspectiva interacionista}

As Ciências Cognitivas (CC) surgiram na década de 1950, a partir de uma iniciativa interdisciplinar motivada pela Sloan Foundation devido à necessidade de pesquisas para esclarecer as relações entre o cérebro e a mente (ANDERSON, 1995; MILLER, 2003).

Para a estruturação desta nova ciência, houve a integração de seis disciplinas que a compuseram, a saber: a psicologia, a linguística, a neurociência, a ciência da computação, a antropologia e a filosofia (BERMUDEZ, 2010), visando compreender como se desenvolve o processo de aquisição de conhecimento na mente humana.

Entendida como “[...] a análise científica (pós-) moderna da mente e do conhecimento em todas as suas dimensões." (VARELA, 1996, p. 9), os objetos de estudos deste campo centralizam-se na percepção, linguagem, inferência e ação. Os paradigmas epistemológicos que estruturam este campo buscam delimitar perspectivas específicas para tratar o fenômeno do conhecimento, a partir de estudos sobre representações mentais internas de objetos que se encontram no mundo externo.

Para isso, foram estruturadas vertentes teóricas para tratar sobre esta questão, das quais se destacam: o cognitivismo clássico, o conexionismo, o enaccionismo e, em especial, o paradigma sociocultural de onde se originou a sociocognição, corrente de pensamento na qual se busca uma aproximação com a memória social proposta por Fentress e Wickham (1992).

Fortemente atrelado às ideias da corrente internalista gramatical/formal de Chomsky, o cognitivismo se estruturou em contraposição ao modelo 
behaviorista, que influenciava os estudos de cognição. Além disso, veio como resposta aos problemas decorrentes do surgimento dos primeiros computadores e o desenvolvimento da Inteligência Artificial, que impulsionaram os estudos sobre esta abordagem (OLIVEIRA, 1990).

Este paradigma indica ainda "[...] que a inteligência consiste em agir sobre uma base de representações que tem uma realidade física sob a forma de código simbólico no cérebro ou no computador." (LAGE; BURNHAM; MICHINEL, 2012, p. 85). Em suma, este modelo se propôs a colocar em foco as representações mentais, pautado no nível lógico-proposicional e na ideia de que o computador é um modelo válido para a compreensão da mente humana, conforme sintetiza Gardner (2003).

A abordagem do conexionismo, assim como o cognitivismo, surge a partir do desenvolvimento da cibernética, porém, a sua principal divergência ao modelo anterior se situa no pensamento de que "[...] a representação mental não é um objeto único (token), um símbolo armazenado, mas encontra-se espalhada sobre um conjunto de unidades integradas [...]" (OLIVEIRA, 2016, p. 97).

Por outro lado, as insatisfações com estes modelos originaram a abordagem sociocognitiva que transpõe os aspectos internos e se propõe a analisar questões externas ao indivíduo - que até então eram ignoradas nas pesquisas -, particularmente no que diz respeito à linguagem e as influências dos fatores sociais e históricos.

Os termos cognição social e sociocognição têm sido utilizados em diferentes contextos, porém, ressaltam-se algumas diferenças no emprego terminológico neste estudo: a cognição social se refere a um paradigma das Ciências Cognitivas, enquanto a sociocognição compreende os estudos da linguagem sob a perspectiva da cognição social.

Partindo deste pressuposto, a linguagem na perspectiva da sociocognição se constitui como objeto de estudo para um grupo constituído por sociolinguistas, etnolinguistas, analistas do discurso, pragmacistas, entre outros, conforme apresenta Koch e Cunha-Lima (2011, p. 254).

A aproximação entre os processos de cognição e a linguística não são recentes. Vygotsky já afirmava que a unidade da relação linguagem-cognição se 
estabelece enunciativamente e ainda, “[...] a linguagem é tida como o principal mediador da interação nas referências do mundo social e cognitivo, de modo a estreitá-los de forma constitutiva." (VYGOTSKY, 1984, p. 61).

A linguagem, nesse sentido, é vista além de uma representação de esquemas mentais ou de uma habilidade cognitiva - como era proposto pelos modelos anteriores da cognição clássica -, mas “[...] como um acontecimento que envolve, de forma imbricada, processos discursivos, cognitivos e gramaticais.” (FERREIRA, 2009, p. 8).

Na visão de Koch e Cunha-Lima (2011), estudos nessa linha propiciam a compreensão sobre como os acontecimentos sociais influenciam na constituição dos significados cognitivamente produzidos. Isto significa dizer que grande parte dos processos cognitivos depende de acontecimentos externos aos indivíduos. Por este motivo, Koch e Cunha-Lima (2011) avaliam ser difícil delimitar se a cognição está dentro ou fora das mentes. Os autores defendem que o que existe, neste caso, é uma inter-relação complexa, que deve ser entendida como um tipo de ação conjunta.

Clark (1996) explica que a ação conjunta se diferencia de ações individuais não meramente pelo número de pessoas envolvidas, mas pela qualidade da ação, pois nela a presença de vários indivíduos e a coordenação entre eles é essencial para que a ação se desenvolva. Nesse sentido, as ações conjuntas que o autor aponta podem ser consideradas como os caminhos que se adotam para o alcance de um objetivo, ou uma finalidade principal, que no caso da linguagem é o compartilhamento do conhecimento.

Em contrapartida, Koch e Cunha-Lima (2011) explicam ainda que as pesquisas no campo da sociocognição têm se voltado para o processamento cognitivo integrado com perspectivas contextuais ao tratamento da cognição humana, em especial, no processamento textual, área de interesse para a Organização do Conhecimento, quando se operam, por exemplo, a indexação e a classificação de conteúdo.

Para as autoras, as ênfases desses estudos centralizam-se na compreensão que vai além das sentenças e busca analisar a construção dos sentidos nos textos de forma mais extensa. Assim, leva-se em consideração o contexto e as formas 
pelas quais os conhecimentos são representados e ativados na memória dos indivíduos.

Textos são também fontes fundamentais para a circulação e construção de conhecimentos partilhados entre indivíduos, sendo uma das mais importantes e centrais formas de cognição social e de organizadores do conhecimento de uma dada cultura. Dado isso, é natural que os estudos de texto tenham um papel central na encruzilhada onde se encontram preocupações com a cognição e com a vida social. (KOCH; CUNHA-LIMA, 2011, p. 293).

Partindo deste ponto, uma significativa parte dos estudos sobre sociocognição se desenvolveu em torno da questão da linguagem no que diz respeito à referenciação, categorização, inferenciação entre outros. Esses estudos têm como objetivo principal explicar como os conhecimentos prévios de mundo e informações contextuais interferem na interpretação e construção do sentido do texto, conforme apresenta Salomão (2003, p. 77)

Enquanto os estudos discursivos mais se guiam pelos aspectos sociais da gênese do sentido (a microfísica da interação, os gêneros textuais, as ordens ideológicas subjacentes), os estudos cognitivos têm preferido focalizar os processos mentais de categorização e esquematização, as projeções entre domínios epistêmicos, as transferências figurativas da estrutura conceptual, o gerenciamento do fluxo discursivo.

Portanto, apesar de ainda não haver uma estruturação de todas as linhas de pesquisas que a sociocognição abarca, este campo aponta para vários direcionamentos e, por isto, a multidisciplinaridade de profissionais que buscam solucionar suas questões, mas principalmente buscam respostas sobre como a sociedade molda a cognição. Resposta essa que interessa também à área de Organização do Conhecimento, uma vez que essa trata exatamente da compreensão dos fenômenos de produção e representação do conhecimento, entendido como produto do processo de cognição humana.

\section{Memória discursiva sociocognitiva: o ponto de interconexões entre a memória social e a sociocognição}

A interseção entre a memória social como fonte de conhecimento e a sociocognição é viável no ponto em que, para a interpretação da memória, é necessária a compreensão do seu contexto. Esse, por sua vez, possui 
características sociocognitivas de seus interlocutores, ou seja, a visão de mundo de quem interpreta os fenômenos da realidade.

O campo que contempla esta discussão, a memória discursiva sociocognitiva, instrumentaliza a análise dos discursos que estão implícitos nos documentos para interpretação da memória social, haja vista que essa é apregoada como fonte de conhecimento por Fentress e Wickham (1992).

Uma vez que se entende a escrita como uma forma de registro de informações, Hobart e Schiffman (2000, p. 23) consideram a perspectiva de um modelo textual da memória, onde os objetos mentais contidos na mente humana são como "pedaços de informações" armazenados por escrito.

$\mathrm{O}$ ponto chave deste argumento centraliza-se sobre a linguagem e a memória, lembrada por Le Goff (2013) em seu estudo sobre "História e memória" ao mostrar que:

\footnotetext{
A utilização de uma linguagem falada, depois escrita, é de fato uma extensão fundamental das possibilidades de armazenamento da nossa memória que, graças a isso, pode sair dos limites físicos do nosso corpo para estar interposta quer nos outros, quer nas bibliotecas. Isto significa que, antes de ser falada ou escrita, existe uma certa linguagem sob a forma de armazenamento de informações na nossa memória. (ATLAN, $1972^{3}$, p. 461 apud LE GOFF, 2013, p. 389).
}

Entende-se que a linguagem por meio da escrita caracteriza-se como a tradução do pensamento, ou seja, uma memória "materializada" no discurso, que muitas vezes serve como apoio para a recordação da história oral, e ainda, como instrumento de preservação do conhecimento.

A memória inscrita nas palavras, nomeada como "palavrasacontecimento" por Moirand (2007), age como rastro psíquico explicitado no discurso e permite rediscutir a ancoragem cognitiva da memória e do discurso, resistindo aos esforços contra o esquecimento e extinção. Desse modo, entendese que "[...] o saber discursivo que torna possível todo dizer, que retorna sob a forma do pré-construído, o já-dito que está na base do dizível, sustentando cada tomada de palavra." (ORLANDI, 2005, p. 31), sendo assim, as palavras - as sustentadas pela memória - são dotadas de sentido. 
Ao contextualizar a memória escrita e/ou discursiva e suas relações no âmbito sociocognitivo-interacionista, Koch (2005) descortina o cenário em que se desenvolvem questões relacionadas à organização e estruturação do conhecimento na mente humana e as formas de acionamento destas informações para solucionar problemas no ambiente onde se desenvolvem as relações sociais - sendo que este ambiente é apenas um dos aspectos a serem analisados.

Para complementar, Machado (2016) explica que o surgimento da memória sociocognitiva, memória discursiva cognitivista ou memória cognitivodiscursiva surge pela integração dos estudos da Filosofia com a visão de Foucault, da História na percepção de Braudel, da ideologia apresentada por Althusser e da teoria do discurso de Pêcheux.

Por meio desta abordagem é possível compreender como e os porquês da cultura e da vida social constituírem as práticas sóciocomunicativas que formam os elementos de representação e memória, pois a cognição é o meio pelo qual a mente humana interpreta e dá sentido ao mundo real por meio da linguagem. Koch sintetiza ao apregoar que "[...] interpretamos e construímos nossos mundos por meio da interação com o entorno físico, social e cultural." $(\mathrm{KOCH}$, 2005, p. 9).

Convém ainda ressaltar que os elementos constituintes da memória discursiva - entendida como uma atividade discursiva - englobam estratégias de referenciação (KOCH; MARCUSCHI, 1998; MARCUSCHI; KOCH, 2002), tendo como base o pressuposto de que o processo construtivista de referência, chamado de objetos-de-discurso, não preexiste naturalmente à atividade cognitiva e interativa dos sujeitos falantes, mas devem ser concebidos como produtos, construídos e reconstruídos por meio das atividades socioculturais (APOTHÉLOZ; REICHLER-BÉGUELIN, 1995).

Em outras palavras, a referenciação é um processo de atribuição de significados - com base nas interações entre os sujeitos em sociedade -, aos objetos-de-discurso, entendidos como o sentido do texto onde se situa o conhecimento. A referenciação não privilegia a relação entre as palavras e as coisas, mas principalmente, a relação intersubjetiva e social nas quais as versões 
do mundo são elaboradas e avaliadas às finalidades práticas e ações em curso dos enunciadores (MONDADA, 2001).

Pode-se visualizar, a partir destas considerações, a interseção entre a construção da memória discursiva no contexto sociocognitivo e os elementos para reflexão do passado por meio dos conhecimentos fornecidos pela memória social, conforme apresentamos no conceito de Fentress e Wickham (1992), uma vez que os autores recomendam uma análise dos argumentos implícitos na sua transmissão, que são conduzidos pela análise dos discursos dos documentos.

Outro ponto elucidado pelos teóricos é a consideração da noção contextual, também defendido nos pressupostos sócio interacionistas de Koch e Cunha-Lima (2011) como a precisão de uma visualização do texto enquanto um exercício complexo que contempla além de questões sobre o discurso, as conjunturas da sua produção, os contextos de uso, além das intenções comunicativas e sociais efetivadas pelos falantes.

Assim sendo, pode-se dizer que a base indicada pela sociocognição para os estudos da memória social, tomando como foco os discursos como fonte de conhecimento, conforme preconizado no campo da memória discursiva sociocognitiva, fornece subsídios para a Organização do Conhecimento no que diz respeito às formas como as comunidades discursivas produzem e organizam seus conhecimentos socialmente construídos em contextos específicos de produção e uso de informação.

\section{Conclusão}

Em linhas gerais, o conceito de memória social defendido neste estudo toma como base o conhecimento que um grupo possui, bem como as interpretações que estão diretamente relacionadas à história e às ideologias implícitas na sua transmissão. A sociocognição, por sua vez, considera que o contexto é determinante para o indivíduo em todas as suas construções sociais do conhecimento, tais como, a linguagem, as suas representações mentais, suas categorizações e a materialização destes processos por meio da escrita no texto.

A memória discursiva sociocognitiva representa as experiências individuais no âmbito do discurso, retratando a memória social e explicitando 
que o sentido não está apenas nas palavras, mas nas experiências moldadas na sociedade que são ativadas no momento da interpretação, sendo, portanto, indícios representativos da memória. Assim, a memória desponta com um propósito no que se refere ao uso de novos métodos para se compreender, identificar e analisar os processos de referenciação, implícitos nos discursos e variáveis em relação ao seu contexto construído sociocognitivamente, ou seja, edificado no partilhamento do conhecimento entre um grupo.

A noção de contexto encontra-se diretamente relacionada às questões de linguagem e a sua maleabilidade para abarcar várias facetas de um domínio que devem ser adotadas para construção de representações da informação e do conhecimento. Os elementos contextuais são originados de várias ordens, seja pelas diferenças culturais entre a comunidade discursiva, pelas necessidades informacionais e pelos pontos de vista divergentes que são construídos por meio das interações comunicativas, ou seja, no cenário social.

Entendemos que a noção de contexto encontra-se implícita na sociocognição ao considerar conjunturas de produção, uso, comunicação e interações sociais de um discurso, e na memória discursiva sociocognitiva ao ressaltar os acontecimentos sociais como portadores de elementos contextuais e na possibilidade de entendimento do passado a partir desses elementos. Logo, percebe-se que os elementos indicados por estes dois campos também estão presentes na abordagem pragmática na Organização do Conhecimento, indicando assim a possibilidade de convergência desses enfoques nos estudos sobre a memória e o conhecimento.

Longe de esgotar as discussões sobre esta temática, pretende-se colocar em foco esta abordagem na Organização do Conhecimento, no sentido de apontar para novos horizontes de pesquisas sob o enfoque do paradigma social da área, bem como a apropriação dessa abordagem para a análise de comunidades discursivas, em especial, nos questionamentos que englobam o uso da linguagem para categorização do conhecimento e as experiências de um domínio. 


\section{Referências}

AMORIM, Igor Soares. Análise de domínio sob a luz do conceito de agenciamento de Gilles Deleuze. 2015. Dissertação (Mestrado em Ciência da Informação) - Centro de Ciências da Educação, Universidade Federal de Santa Catarina, Florianópolis, 2015.

ANDERSON, John. R. Cognitive psychology and its implications. New York: Freeman, 1995.

APOTHÉLOZ, Denis; REICHLER-BÉGUELIN, Marie-José. Construction de la référence et stratégies de désignation. TRANEL, Neuchâtel, n. 23, p. 227-271, déc. 1995.

BERGSON, Henri. Matéria e memória: ensaio da relação do corpo com o espírito. São Paulo: Martins Fontes, 2010.

BERMUDEZ, José Luis. Cognitive science: an introduction to the science of the mind. New York: Cambridge University, 2010.

CLARK, Herbert H. Using language. Cambridge: Cambridge University Press, 1996.

COLLIS, Jill; HUSSEY, Roger. Pesquisa em administração: um guia prático para alunos de graduação e pós-graduação. 2. ed. Porto Alegre: Bookman, 2005.

FENTRESS, James; WICKHAM, Chris. Social memory: new perspectives on the past. Cambridge: Blackwell, 1992.

FERREIRA, Tânia Brisanti. Sociocognição: uma abordagem relevante para a compreensão dos processos de construção de sentido. In: SEMANA DE HUMANIDADES, 17, 2009, Natal. Anais... Natal: UFRN, 2009. p. 1-10.

GARDNER, Howard. A nova ciência da mente. São Paulo: EDUSP, 2003.

GUIMARÃES, Arthur; GOMYDE, Heloisa. Émile Durkheim: para o sociólogo francês, a principal função do professor é formar cidadãos capazes de contribuir para a harmonia social. 2011.

HALBWACHS, Maurice. A memória coletiva. São Paulo: Centauro, 2004.

HIGGINS, E. Tory. Social cognition: learning about what matters in the social world. European Journal of Social Psychology, Sussex, v. 30, n. 1, p. 3-39, Jan./Feb. 2000. 
HJORLAND, Birger. Epistemology and the socio-cognitive perspective in information science. Journal of the American Society for Information Science and Technology, New York, v. 53, n. 4, p. 257-270, 2002.

HOBART, Michael E.; SCHIFFMAN, Zachary S. Information ages: literacy, numeracy, and the computer revolution. Maryland: John Hopkings University Press, 2000.

JARDIM, José Maria. A invenção da memória nos arquivos públicos. Ciência da Informação, Brasília, v. 25, n. 2, p. 1-13, 1995.

KOCH, Ingedore Grunfeld Villaça. Construção dos sentidos no discurso: uma abordagem sociocognitiva. Revista Investigações, Recife, v. 18, n. 2, 2005.

KOCH, Ingedore Grunfeld Villaça; CUNHA-LIMA, Maria Luiza. Do cognitivismo ao sociocognitivismo. In: MUSSALIM, Fernanda; BENTES, Ana Christina (Org.). Introdução à linguística: volume 3: fundamentos epistemológicos. 5. ed. São Paulo: Cortez, 2011.

KOCH, Ingedore Grunfeld Villaça; MARCUSCHI, Luiz Antônio. Processos de referenciação na produção discursiva. DELTA, São Paulo, v. 14, n. esp, p. 169190, 1998.

LAGE, Ana Lúcia; BURNHAM, Teresinha Fróes; MICHINEL, José Luis. Abordagens epistemológicas da cognição: a análise cognitiva na investigação da construção de conhecimento. In: BURNHAM, Teresinha Fróes et al. (Org.). Análise cognitiva e espaços multireferenciais de aprendizagem: currículo, educação à distância e gestão/difusão do conhecimento. Salvador: EDUFBA, 2012.

LE GOFF, Jacques. História e memória. 7. ed. Campinas: Ed. UNICAMP, 2013.

MACHADO, Bruno Focas Vieira. A memória cognitivo-discursiva: entre discurso, psicanálise e cognição. Revista de Estudos da Linguagem, Belo Horizonte, v. 24, n. 1, p. 225-255, 2016.

MARCUSCHI, Luiz Antônio; KOCH, Ingedore Grunfeld Villaça. Estratégias de referenciação e progressão referencial na língua falada. In: ABAURRE, Maria Bernadete (Org.). Gramática do português falado: volume III. Campinas: Ed. UNICAMP, 2002.

MILLER, George A. The cognitive revolution: a historical perspective. Trends in Cognitive Science, Cambridge, v. 7, n. 3, p. 141-144, Mar. 2003.

MOIRAND, Sophie. Discours, mémoires et contextes: à propos du fonctionnement de l'allusion dans la presse. Corela, Poitiers, n. HS-6, nov. 2007. 
MONDADA, Lorenza. Gestion du topic et organization de la conversation. Cadernos de Estudos Linguísticos, Campinas, v. 41, p. 7-36, 2001.

MONTYSUMA, Marcos; KARPINSKI, Cezar. Memória e história oral. Indaial: Grupo UNIASSELVI, 2010.

OLICK, Jeffrey K.; ROBBINS, Joyce. Social memory studies: from "collective memory" to the historical sociology of mnemonic practices. Annual Review of Sociology, Palo Alto, v. 4, p. 105-140, 1998.

OLIVEIRA, Eliane Braga de; RODRIGUES, Georgete Medleg. As concepções da memória na ciência da informação no Brasil: estudo preliminar sobre a ocorrência do tema na produção científica. In: ENCONTRO NACIONAL DE PESQUISA EM CIÊNCIA DA INFORMAÇÃO, 9., 2008, São Paulo. Anais... São Paulo, 2008.

OLIVEIRA, Luis Felipe. O debate sobre o representacionalismo nas ciências cognitivas. Kínesis, Marília, v. 8, n. 17, p. 85-114, jul. 2016.

OLIVEIRA, Marcos Barbosa de. Cognitivismo e ciência cognitiva. Trans/Form/Ação, São Paulo, v. 13, p. 85-93, 1990.

ORLANDI, Eni. Análise de discurso: princípios e procedimentos. 6. ed. Campinas: Pontes, 2005.

POLLAK, Michael. Memória, silêncio e esquecimento. Estudos Históricos, Rio de Janeiro, v. 2, n. 3, p. 3-15, 1989.

SALOMÃO, Maria Margarida Martins. Razão, realismo e verdade: o que nos ensina o estudo sociocognitivo da referência. Caderno de Estudos Linguísticos, Campinas, n. 44, p. 71-83, jan./jun. 2003.

TULVING, Endel. Elements of episodic memory. New York: Oxford University Press, 1983.

VARELA, Francisco. Invitation aux sciences cognitives. 2. ed. Paris: Éditions du Seuil, 1996.

VYGOTSKY, Lev Semyonovich. A formação social da mente. São Paulo: Martins Fontes, 1984. 


\title{
The relationship between the social memory and sociocognition: in search of the social context in the Knowledge Organization
}

\begin{abstract}
This article aims to highlight the relation between social memory and social cognition and the perspectives of understanding the context for knowledge organization. The research is exploratory and adopts as a methodological procedure the bibliographic research. It understands social memory as a source of knowledge that presupposes the collective experience of a group. The sociocognition, the studies on the language and the discussions that this field contemplates from the perspective of the paradigm of the social cognition are characterized. It points to the intersection between social memory and sociocognition, at the point where, for the interpretation of memory, it is necessary to understand its context, which has the sociocognitive characteristics of its interlocutors, that is, the worldview of the interpreter. The field of sociocognitive discursive memory as the framework where the sociocommunicative practices of representation and memory are constituted is elucidated. The study shows that the questions about the discourse, the contexts of use, the communicative and social intentions made by the speakers are elements of study in the field of sociocognitive discursive memory. Notes that the basis indicated by sociocognition for the study of social memory provides the basis for the organization of knowledge with respect to the ways in which discursive communities produce and organize their socially constructed knowledge.
\end{abstract}

Keywords: Social memory. Sociocognition. Sociocognitive discursive memory. Knowledge organization.

Recebido: 06/02/2017

Aceito: 06/07/2017

1 CAPURRO, Rafael. Epistemologia e Ciência da Informação. 2003. Disponível em: <www.capurro.de/enancib_p.htm>. Apud Oliveira e Rodrigues (2008).

${ }^{2}$ BERGSON, Henri. Matéria e memória: ensaio sobre a relação do corpo com o espírito. São Paulo: Martins Fontes, 1999. Apud Montysuma e Karpinski (2010).

3 ATLAN, Henri. Du bruit comme principe d'auto-organisation. Communications, [S.1.], v. 18, n. 1, p. 21-36, 1972. Apud Le Goff (2013). 